\title{
The Impact of Sinusoidal Surface Temperature on the Natural Convective Flow of a Ferrofluid along a Vertical Plate
}

\author{
Essam R. EL-Zahar ${ }^{1,2, *}$, Ahmed M. Rashad ${ }^{3, *}$ (1) and Laila F. Seddek ${ }^{1,4}$ \\ 1 Department of Mathematics, College of Science and Humanities in Al-Kharj, Prince Sattam bin Abdulaziz \\ University, Al-Kharj 11942, Saudi Arabia; leseddek@zu.edu.eg \\ 2 Department of Basic Engineering Science, Faculty of Engineering, Menoufia University, \\ Shebin El-Kom 32511, Egypt \\ 3 Department of Mathematics, Faculty of Science, Aswan University, Aswan 81528, Egypt \\ 4 Department of Engineering Mathematics and Physics, Faculty of Engineering, Zagazig University, Zagazig \\ 44519, Egypt \\ * Correspondence: er.elzahar@psau.edu.sa (E.R.E.-Z.); am_rashad@yahoo.com (A.M.R.)
}

Received: 25 September 2019; Accepted: 22 October 2019; Published: 25 October 2019

\begin{abstract}
The spotlight of this investigation is primarily the effectiveness of the magnetic field on the natural convective for a $\mathrm{Fe}_{3} \mathrm{O}_{4}$ ferrofluid flow over a vertical radiate plate using streamwise sinusoidal variation in surface temperature. The energy equation is reduplicated by interpolating the non-linear radiation effectiveness. The original equations describing the ferrofluid motion and energy are converted into non-dimensional equations and solved numerically using a new hybrid linearization-differential quadrature method (HLDQM). HLDQM is a high order semi-analytical numerical method that results in analytical solutions in $\eta$-direction, and so the solutions are valid overall in the $\eta$ domain, not only at grid points. The dimensionless velocity and temperature curves are elaborated. Furthermore, the engineering curiosity of the drag coefficient and local Nusselt number are debated and sketched in view of various emerging parameters. The analyzed numerical results display that applying the magnetic field to the ferroliquid generates a dragging force that diminishes the ferrofluid velocity, whereas it is found to boost the temperature curves. Furthermore, the drag coefficient sufficiently minifies, while an evolution in the heat transfer rate occurs as nanoparticle volume fraction builds. Additionally, the augmentation in temperature ratio parameter signifies a considerable growth in the drag coefficient and Nusselt number. The current theoretical investigation may be beneficial in manufacturing processes, development of transport of energy, and heat resources.
\end{abstract}

Keywords: natural convection; Ferrofluid; thermal radiation; magnetic field

\section{Introduction}

Nanofluid progress-related innovations have lately pulled in the consideration of numerous scientists. Analysts have centered to consider numerous logical fields, including vitality, cooling, hardware and microelectronics, transportation, new energies, medication, and vitality, and fuel the board with the assistance of nanofluids. The use of a nanofluid in a liquid stream framework requires information about the liquid flow properties, particularly its thickness. Along these lines, scientists started looking into nanofluid thickness to determine the siphoning power required for the use of nanofluids in heat exchangers. In regards to these applications, Choi [1] and Buongiorno [2] called attention to different realities concerning nanofluids. They referred to a liquid including a dispersion of nanoparticles having greater thermal conductivity in a primary fluid. Kuznetsov and Nield [3] construed the idea of nanofluid flow by free convective adjacent to a vertical plate. They proposed a 
naturalistic kind of boundary condition which considers the effectiveness of thermophoresis Brownian movement. Khan and Pop [4] utilized the idea in [3] to contemplate the principal deal with nanofluid flow over an extending sheet. Bachok et al. [5] implemented an investigation of nanofluid flow past a semi-infinite plate. Rashad et al. [6] inspected the enhancement of heat transfer in a Darcy nanofluid convective flow past a porous cone. Rashad et al. [7] also probed the non-Darcy problem of a thermally stratified nanofluid flow over a vertical cylinder. They explored how heat transfer rate declined as the Brownian motion parameter boosted. However, abundant fundamental investigations are performed in this field, as can be seen in [8-13].

Magnetic nanofluids (or ferrofluids) are the colloidal suspension of magneto-nanoparticles in a regular fluid (water, kerosene, mineral oil). Ferrofluids are magnetically controllable nanofluids, which contain magnetic nanoparticles, such as iron, cobalt, nickel, magnetite, ferrite, spinel-type. Since ferrofluids can be easily manipulated by means of an external magnetic force, the use of these fluids is promoted in numerous significant industrial applications, such as in vacuum seals, vibration-dampers, loudspeakers, shock absorbers, transformers coolant, and stepper motors [14-19]. Hayat et al. [20,21] probed the magneto-flow of Newtonian and viscoelastic nanofluids over a radiate stretchable surface. Rashad [22] explained the effectiveness of radiation phenomena on magneto-ferrofluid flow past a nonisothermal wedge. Waqas et al. [23] inspected the influence of thermal radiation on the magneto-nanofluid model. EL-Kabeir et al. [24] broadened unsteady magneto slip ferrofluid flow through a stretchable sheet.

In numerous investigations, the geometric surfaces are scrutinized at a uniform temperature or uniform heat flux, whilst in effective situations these thermal boundary conditions rarely exist. Variation in temperature distribution at surfaces is beneficial for several engineering and industrial applications. In cases like solar energy combination and the refrigeration of electronic compositions, the thermally efficacious surfaces might be able to maintain sinusoidal variation in temperature profiles due to shading or other impacts in the framework. Thus, the investigation on magneto-convective for ferrofluid flow over a heated vertical surface due to streamwise sinusoidal variation is important in such cases. However, propelled by the previously mentioned research, the intention here is to investigate the magneto hydrodynamics (MHD) natural convective ferrofluid flow over a radiate plate using the streamwise sinusoidal diversity in wall temperature. Representative outcomes for the speed, temperature, drag coefficient, and Nusselt number clarify the efficacy of thermal radiation, magnetic field, and nanoparticles volume fraction. The original equations describing the ferrofluid motion and energy are converted into non-dimensional nonlinear partial differential equations (PDEs) and solved computationally, employing a novel hybrid linearization-differential quadrature method (HLDQM). HLDQM is a high order semi-analytical numerical method that has advantages with respect to other numerical methods, such as how the resulting approximate solutions of the nonlinear PDEs are analytical solutions in $\eta$-direction, and so the solutions are valid overall in the $\eta$ domain, not only at grid points. This property allows us to easily get solutions at intermediate grid points without interpolation, and consequently different grid adaptation techniques can be used. Furthermore, the mode can be utilized directly for systems of high-order differential equations with no need to convert them into first-order systems.

\section{Governing Equations}

In this section, a mathematical model is derived to explore the effectiveness of non-linear thermal radiation on the magneto-natural convective ferrofluid flow over a non-isothermal semi-infinite vertical plate using the sinusoidal surface temperature diversities. The nanoliquid in the current exploration was composed of an iron oxide nanoparticle $\left(\mathrm{Fe}_{3} \mathrm{O}_{4}\right)$ added to a base liquid (kerosene oil) [22]. The graphical view of the problem and coordinate system of such a flow model are exhibited in Figure 1. A robust continuous magnetic field $B_{0}$ was utilized orthogonal to the flow trend. The plate surface was heated due to the sinusoidal temperature profile of the form $T=T_{\infty}+\left(T_{w}-T_{\infty}\right)(1+\Omega \sin (\pi \tilde{x} / L))$, where $\Omega$ is the relative amplitude of wall temperature diversities, $T_{w}$ is the mean all temperature, 
$T_{\infty}$ is the ambient temperature far away from the plate surface, and $2 L$ is the wave longitude of diversities. Besides this, the incompressible feature of liquid is treated. Keeping the previously mentioned presumptions in treatment, we have $[25,26]$ :

$$
\begin{gathered}
\frac{\partial \widetilde{u}}{\partial \widetilde{x}}+\frac{\partial \widetilde{v}}{\partial \widetilde{y}}=0, \\
\widetilde{u} \frac{\partial \widetilde{u}}{\partial \widetilde{x}}+\widetilde{v} \frac{\partial \widetilde{u}}{\partial \widetilde{y}}=\frac{\mu_{f f}}{\rho_{f f}} \frac{\partial^{2} \widetilde{u}}{\partial \widetilde{y}^{2}}+\frac{g(\rho \beta)_{f f}}{\rho_{f f}}\left(T-T_{\infty}\right)-\frac{\sigma_{f f} B_{0}^{2}}{\rho_{f f}} \widetilde{u}, \\
\widetilde{u} \frac{\partial T}{\partial \widetilde{x}}+\widetilde{v} \frac{\partial T}{\partial \widetilde{y}}=\alpha_{f f} \frac{\partial^{2} T}{\partial \widetilde{y}^{2}}-\frac{1}{\left(\rho C_{p}\right)_{f f}} \frac{\partial q_{r}}{\partial \widetilde{y}} .
\end{gathered}
$$

The following imposed conditions of the model are [25]:

$$
\begin{gathered}
\tilde{u}=0, \widetilde{v}=0, T=T_{\infty}+\left(T_{w}-T_{\infty}\right)(1+\Omega \sin (\pi \tilde{x} / L)), \text { at } \tilde{y}=0, \\
\widetilde{u}=0, T=T_{\infty}, \text { as } \widetilde{y} \rightarrow \infty .
\end{gathered}
$$

Here, $(\widetilde{u}, \widetilde{v})$ are dimensional velocity components along dimensional $(\widetilde{x}, \widetilde{y})$-axes; $T$ is the ferrofluid temperature; $B_{0}$ is the magnetic induction; $g$ is the gravitational acceleration; $q_{r}$ is the radiation heat flux; $\beta$ is the thermal expansion coefficient; $\rho$ is the density; $\mu$ is the dynamic viscosity; $\alpha$ is the thermal diffusivity; $\left(\rho C_{p}\right)$ is the heat capacitance; $\sigma_{f f}$ is the electrical conductivity of the ferrofluid, which are utilized as [22]:

$$
\begin{aligned}
& \rho_{f f}=(1-\phi) \rho_{f}+\phi \rho_{s}, \mu_{f f}=\frac{1}{(1-\phi)^{2.5}}, \alpha_{f f}=\frac{k_{f f}}{\left(\rho C_{p}\right)_{f f}} \\
& \left(\rho C_{p}\right)_{f f}=(1-\phi)\left(\rho C_{p}\right)_{f}+\phi\left(\rho C_{p}\right)_{s^{\prime}}(\rho \beta)_{f f}=(1-\phi)(\rho \beta)_{f}+\phi(\rho \beta)_{s} \\
& \frac{k_{f f}}{k_{f}}=\frac{\left(k_{s}+2 k_{f}\right)-2 \phi\left(k_{f}-k_{s}\right)}{\left(k_{s}+2 k_{f}\right)+\phi\left(k_{f}-k_{s}\right)}, \frac{\sigma_{f f}}{\sigma_{f}}=1+\frac{3\left(\sigma_{s} / \sigma_{f}-1\right) \phi}{\left(\sigma_{s} / \sigma_{f}+2\right)-\left(\sigma_{s} / \sigma_{f}-1\right) \phi}
\end{aligned}
$$

Above, subscripts " $f$ ", " $f f$ ", and " $s$ " nominate base fluid, ferrofluid, and ferromagnetic particle, respectively. $\Phi$ is the solid volume fraction, $k_{f f}$ is the thermal conductivity of ferrofluid. The effective thermal and physical properties of $\left(\mathrm{Fe}_{3} \mathrm{O}_{4}\right)$ kerosene ferrofluid have been registered in [22].

To obtain the non-similar result, we used the next dimensionless variables:

$$
x=\frac{\widetilde{x}}{L}, \widetilde{u}=\frac{v_{f} G r_{L}^{1 / 2}}{L} u, \widetilde{v}=\frac{v_{f} G r_{L}^{1 / 4}}{L} v, y=\frac{G r_{L}^{1 / 4}}{L} \widetilde{y}, \theta=\frac{T-T_{\infty}}{T_{w}-T_{\infty}}, G r_{L}=\frac{g \beta_{f}\left(T_{w}-T_{\infty}\right) L^{3}}{v_{f}^{2}},
$$

where $u_{-}, v$ are dimensionless fluid velocities in the dimensionless; $x, y$ are directions; $\theta$ is the dimensionless temperature; and $G r_{L}$ is the Grashof number.

In the implementation of the Rosseland approximation, $q_{r}$ is defined as,

$$
q_{r}=-\frac{4 \sigma_{1}}{3\left(\alpha_{r}+\sigma_{s}\right)} \frac{\partial T^{4}}{\partial \widetilde{y}}
$$

where $\alpha_{r}$ is the Rosseland and mean absorption coefficient; $\sigma_{1}$ is the Stefan-Boltzmann constant; $\sigma_{s}$ is the scattering coefficient. Applying (5)-(7) in (1)-(4), one can have:

$$
\begin{gathered}
\frac{\partial u}{\partial x}+\frac{\partial v}{\partial y}=0 \\
u \frac{\partial u}{\partial x}+v \frac{\partial u}{\partial y}=\Lambda_{1}(\phi) \frac{\partial^{2} u}{\partial y^{2}}+\Lambda_{2}(\phi) \theta-\Lambda_{4}(\phi) H a^{2} u
\end{gathered}
$$




$$
\begin{gathered}
u \frac{\partial \theta}{\partial x}+v \frac{\partial \theta}{\partial y}=\frac{1}{\operatorname{Pr} \frac{k_{f f}}{k_{f}} \Lambda_{3}(\phi) \frac{\partial^{2} \theta}{\partial y^{2}}+\frac{4 R d}{3 \operatorname{Pr}} \Lambda_{3}(\phi) \frac{\partial}{\partial y}\left[1+\left(\theta_{w}-1\right) \theta\right]^{3} \frac{\partial \theta}{\partial y},} \\
u=0, v=0, \theta=1+\Omega \sin (\pi x), \text { at } y=0, \\
u=0, \theta=0, \text { as } y \rightarrow \infty,
\end{gathered}
$$

where $H a=\frac{B_{0} L}{G r_{L}^{1 / 4}} \sqrt{\sigma_{f} / \mu_{f}}$ is the Hartmann number, $R d=\frac{4 \sigma T_{\infty}^{3}}{k_{f}\left(\alpha_{r}+\sigma_{s}\right)}$ is the radiation parameter, $\operatorname{Pr}=v_{f} / \alpha_{f}$ is the Prandtl number, and $\theta_{w}=\frac{T_{w}}{T_{\infty}}$ is the temperature ratio parameter.

$$
\begin{gathered}
\Lambda_{1}(\phi)=\frac{1}{(1-\phi)^{2.5}\left[1-\phi+\phi\left(\rho_{s} / \rho_{f}\right)\right]}, \quad \Lambda_{2}(\phi)=\frac{\left[1-\phi+\phi\left((\rho \beta)_{s} /(\rho \beta)_{f}\right)\right]}{\left[1-\phi+\phi\left(\rho_{s} / \rho_{f}\right)\right]} \\
\Lambda_{4}(\phi)=\frac{\sigma_{f f}}{\sigma_{f}\left[1-\phi+\phi\left(\rho_{s} / \rho_{f}\right)\right]}, \quad \Lambda_{3}(\phi)=\frac{1}{\left[1-\phi+\phi\left(\left(\rho C_{p}\right)_{s} /\left(\rho C_{p}\right)_{f}\right)\right]}
\end{gathered}
$$

According to [26], the stream function $\psi$ is known as $u=\partial \psi / \partial y, v=-\partial \psi / \partial x$ and then Equation (8) is attained involuntarily. Referred by the famous non-similarity style congruent to a constant wall temperature, one can apply the following substitution:

$$
\xi=x, \eta=y / \xi^{1 / 4}, \psi=\xi^{3 / 4} f(\xi, \eta), \theta=\theta(\xi, \eta),
$$

into Equations (8) through (10), to obtain:

$$
\begin{gathered}
\Lambda_{1}(\phi) f^{\prime \prime \prime}+\frac{3}{4} f f^{\prime \prime}-\frac{1}{2} f^{\prime 2}+\Lambda_{2}(\phi) \theta-\Lambda_{4}(\phi) H a^{2} \xi^{1 / 2} f^{\prime}=\xi\left(f^{\prime} \frac{\partial f^{\prime}}{\partial \xi}-f^{\prime \prime} \frac{\partial f}{\partial \xi}\right), \\
\frac{1}{\operatorname{Pr}} \frac{k_{f f}}{k_{f}} \Lambda_{3}(\phi) \theta^{\prime \prime}+\frac{4 R_{d}}{3 \operatorname{Pr}} \Lambda_{3}(\phi)\left[\left(1+\left(\theta_{w}-1\right) \theta\right)^{3} \theta^{\prime}\right]^{\prime}+\frac{3}{4} f \theta^{\prime}=\xi\left(f^{\prime} \frac{\partial \theta}{\partial \xi}-\theta^{\prime} \frac{\partial f}{\partial \xi}\right) .
\end{gathered}
$$

The accompanying non-dimensional boundary conditions become:

$$
\begin{gathered}
f^{\prime}(\xi, 0)=0, f(\xi, 0)=0, \theta(\xi, 0)=1+\Omega \sin (\pi \xi), \\
f^{\prime}\left(\xi, \eta_{\infty}\right)=\theta\left(\xi, \eta_{\infty}\right)=0, \quad \eta_{\infty} \rightarrow \infty .
\end{gathered}
$$

Finally, the expression of drag friction $C_{f}$ and local Nusselt number $\left(N u_{x}\right)$ are written as:

$$
C_{f} G r_{x}^{1 / 4} / 2=\frac{1}{(1-\phi)^{2.5}} f^{\prime \prime}(\xi, 0), N u_{x} G r_{x}^{-1 / 4}=-\left(\frac{k_{f f}}{k_{f}}+\frac{4 \theta_{w}^{3}}{3} R_{d}\right) \theta^{\prime}(\xi, 0) .
$$

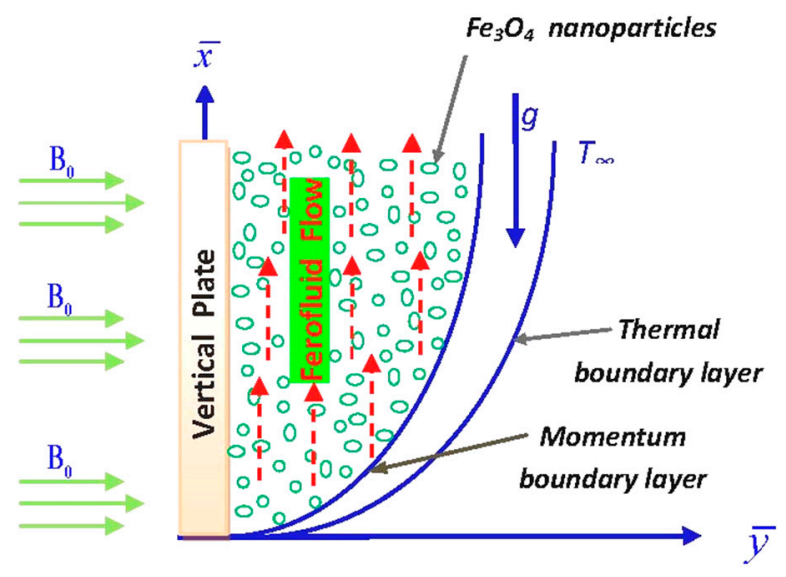

Figure 1. Geometry of the flow process. 


\section{Hybrid Linearization-Differential Quadrature Method (HLDQM)}

In this segment, we exhibit the computational technique employed to solve the nonlinear system of PDEs (14)-(15) with boundary conditions (16). Newton's linearization method (NLM) was utilized to linearize the non-linear system (14)-(16), which was subsequently solved using the differential quadrature method (DQM) [27-39] and two-point backward finite difference method. Applying NLM on (14)-(16) gives:

$$
\begin{aligned}
& \Lambda_{1}(\phi) f_{n+1}^{(3)}+a 1_{n} f_{n+1}^{(2)}+a 2_{n} f_{n+1}^{(1)}+a 3_{n} f_{n+1}+a 4_{n}=a 5_{n} \frac{\partial f_{n+1}^{(1)}}{\partial \xi}+a 6_{n} \frac{\partial f_{n+1}}{\partial \xi} \\
& b 1_{n} \theta_{n+1}^{(2)}+b 2_{n} \theta_{n+1}^{(1)}+b 3_{n} \theta_{n+1}+b 4_{n}=b 5_{n} \frac{\partial \theta_{n+1}}{\partial \xi}+b 6_{n} \frac{\partial f_{n+1}}{\partial \xi}, \quad n=0,1,2, \ldots
\end{aligned}
$$

with boundary conditions:

$$
\begin{gathered}
f_{n+1}(\xi, 0)=0, \quad f_{n+1}^{(1)}(\xi, 0)=0, \quad \theta_{n+1}(\xi, 0)=1+\Omega \sin (\pi \xi) \\
f_{n+1}^{(1)}\left(\xi, \eta_{\infty}\right)=\theta_{n+1}\left(\xi, \eta_{\infty}\right)=0, \quad n=0,1,2, \ldots
\end{gathered}
$$

The coefficients in (18) are defined by:

$$
\begin{aligned}
& a 1_{n}=\frac{3}{4} f_{n}+\xi \frac{\partial f_{n}}{\partial \xi}, a 2_{n}=-\left(\Lambda_{4} H a^{2} \xi^{1 / 2}+\xi \frac{\partial f_{n}^{(1)}}{\partial \xi}+f_{n}^{\prime}\right), a 5_{n}=-\xi f_{n}^{(2)}, a 6_{n}=\xi f_{n}^{(1)}, \\
& a 3_{n}=\frac{3}{4} f_{n}^{(2)}, a 4_{n}=\xi\left(f_{n}^{(1)} \frac{\partial f_{n}^{(1)}}{\partial \xi}-f_{n}^{(2)} \frac{\partial f_{n}}{\partial \xi}\right)+\frac{1}{2}\left(f_{n}^{(1)}\right)^{2}-\frac{3}{4} f_{n} f_{n}^{(2)}+\Lambda_{2} \theta_{n} \\
& b 1_{n}=\frac{1}{\operatorname{Pr}} \frac{k_{f f}}{k_{f}} \Lambda_{3}(\phi)+\frac{4 R_{d}}{3 \operatorname{Pr}} \Lambda_{3}(\phi) A^{3}, \quad b 2_{n}=\frac{3}{4} f_{n}+\xi \frac{\partial f_{n}}{\partial \xi}+\frac{4 R_{d}}{\operatorname{Pr}} \Lambda_{3}(\phi) A^{2}\left(\theta_{w}-1\right) \\
& b 3_{n}=\frac{4 R_{d}}{\operatorname{Pr}} \Lambda_{3}(\phi) A\left(\theta_{w}-1\right)\left(A \theta_{n}^{(2)}+2\left(\theta_{w}-1\right) \theta_{n}^{(1)}\right), b 5_{n}=-\xi f_{n}^{(1)}, b 6_{n}=0 \\
& b 4_{n}=\frac{-1}{\operatorname{Pr}}\left(4\left(\theta_{w}-1\right) A\left(2\left(\theta_{w}-1\right) \theta_{n}^{(1)}+\theta_{n}^{(1)} A\right) \Lambda_{3}(\phi) R_{d} \theta_{n}\right)
\end{aligned}
$$

where $A_{n}=1+\left(\theta_{w}-1\right) \theta_{n}$ and $n=0,1,2, \ldots$

In (18)-(20), the dependent variables subscripted by $n$ are known from the previous Newton's iteration and their updated values at the current iteration are subscripted by $n+1$. To solve the linearized system (18)-(19), we employed the DQM using Lagrange interpolation polynomial as our based functions over Chebyshev-Gauss-Lobatto grid points in $\eta$-direction and the two-point backward finite difference method in $\xi$-direction. The problem mesh grid-points $\left(\xi_{j}, \eta_{\bar{k}}\right)$ are defined by $[30,33,38]$ :

$$
\xi_{j}=j \Delta_{\xi}, \eta_{\bar{k}}=\frac{1}{2}\left[1-\cos \frac{\bar{k} \pi}{N_{\bar{\eta}_{\infty}}-1}\right] \bar{\eta}_{\infty}, j=0,1, \ldots N_{\xi}-1, \bar{k}=0,1, \ldots N_{\bar{\eta}_{\infty}}-1
$$

where $\Delta_{\xi}$ is the step-size in $\xi$-direction, $\bar{\eta}_{\infty}$ is the initial estimation of $\eta_{\infty}$, and $N_{\xi}, N_{\bar{\eta}_{\infty}}$ are the number of grid points in the $\xi$ and $\eta$-directions, respectively. The linear system (18) was transformed in the $\eta$-direction into algebriac systems of equations using the following linear transformations:

$$
\left.\begin{array}{l}
\mathbf{F}_{n+1,(j, \bar{k})}^{(m)}=\mathbf{D}^{m} \mathbf{F}_{n+1,(j, \bar{k})}, \quad m=1,2,3, \\
\boldsymbol{\Theta}_{n+1,(j, \bar{k})}^{(\bar{m})}=\mathrm{D}^{\widehat{m}} \mathbf{\Theta}_{n+1,(j, \bar{k})}, \quad \widehat{m}=1,2,
\end{array}\right\}, j=0,1, \ldots N_{\xi}-1, \bar{k}=0,1, \ldots N_{\bar{\eta}_{\infty}}-1,
$$

where $\mathbf{D}^{m}$ and $\mathrm{D}^{\widehat{m}}$ are the $m^{\text {th }}$ and $\widetilde{m}^{\text {th }}$ derivatives of the Chebyshev differentiation matrices defined in $[28,30], \mathbf{F}_{n+1,(j, \bar{k})}$ and $\boldsymbol{\Theta}_{n+1,(j, \bar{k})}$ are the solution vectors $\left[f_{n+1}\left(\xi_{j}, \eta_{\bar{k}}\right)\right]_{\bar{k}=0}^{N_{\bar{\eta}_{\infty}}}$ and $\left[\theta_{n+1}\left(\xi_{j}, \eta_{\bar{k}}\right)\right]_{\bar{k}=0}^{N_{\bar{\eta}_{\infty}}}$, respectively, while $\mathbf{F}_{n+1,(j, \bar{k})}^{(m)}$ and $\mathbf{\Theta}_{n+1,(j, \bar{k})}^{(\widehat{m})}$ are the solution-derivative vectors $\left[f_{n+1}^{(m)}\left(\xi_{j}, \eta_{\bar{k}}\right)\right]_{\bar{k}=0}^{N_{\bar{\eta}_{\infty}}}$ and 
$\left[\theta_{n+1}^{(\widehat{m})}\left(\xi_{j}, \eta_{\bar{k}}\right)\right]_{\bar{k}=0}^{N_{\bar{\eta}_{\infty}}}$, respectively. In the $\xi$-direction, all first-order derivatives with respect to $\xi$ are discretized using a two-point backward finite difference scheme similar to:

$$
\left.\frac{\partial}{\partial \xi}\right|_{n+1,(j, \bar{k})}=\frac{n+1,(j, \bar{k})-n+1,(j-1, \bar{k})}{\Delta_{\xi}}, j=0,1, \ldots N_{\xi}-1, \bar{k}=0,1, \ldots N_{\bar{\eta}_{\infty}}-1,
$$

where $=f(\xi, \eta), f^{(1)}(\xi, \eta)$, or $\theta(\xi, \eta)$. By applying DQM on (18), we have the following sequence of algebraic systems at $\xi_{j}, j=0,1, \ldots N_{\xi}-1$,:

$$
\begin{aligned}
& \left(\Lambda_{1}(\phi) \mathbf{D}^{3}+\boldsymbol{a} \mathbf{1}_{n} \mathbf{D}^{2}+\left(\boldsymbol{a} \mathbf{2}_{n}-\frac{a 5_{n}}{\Delta_{\xi}}\right) \mathbf{D}^{1}+\boldsymbol{a} \mathbf{3}_{n}-\frac{a 6_{n}}{\Delta_{\xi}}\right) \mathbf{F}_{n+1,(j, \bar{k})}=-\left(\frac{a 6_{n}}{\Delta_{\xi}}-\frac{a 5_{n}}{\Delta_{\xi}} \mathbf{D}^{1}\right) \mathbf{F}_{n+1,(j, \bar{k})}-\boldsymbol{a} \mathbf{4}_{n} \\
& \left(\boldsymbol{b} \mathbf{1}_{n} \mathrm{D}^{2}+\boldsymbol{b} \mathbf{2}_{n} \mathrm{D}^{1}+\boldsymbol{b} \mathbf{3}_{n}-\frac{b 5_{n}}{\Delta_{\xi}}\right) \boldsymbol{\Theta}_{n+1,(j, \bar{k})}=-\frac{b 5_{n}}{\Delta_{\xi}} \mathbf{\Theta}_{n+1,(j, \bar{k})}-\boldsymbol{b} \mathbf{4}_{n}, \quad j=0,1, \ldots N_{\xi}-1,
\end{aligned}
$$

where the coefficients in (24) are vector forms of the coefficients defined in (20).

System (24) combined with its boundary conditions (19) was solved iteratively at $\xi_{j}, j=$ $0,1, \ldots N_{\xi}-1$, and the iterative procedure was stopped when the difference between the results in two successive iterations was less than $10^{-5}$ :

$$
E_{j}=\max \left(\left\|\mathbf{F}_{n+1,(j, \bar{k})}-\boldsymbol{F}_{n+1,(j, \bar{k})}\right\|_{\infty},\left\|\boldsymbol{\Theta}_{n+1,(j, \bar{k})}-\boldsymbol{\Theta}_{n+1,(j, \bar{k})}\right\|\right)<10^{-5}, j=0,1, \ldots N_{\xi}-1 .
$$

Figure 2a,b was prepared for the comparison of the numerical solutions established by the Rees [25] and Molla et al. [26] approaches and the HLDQM solution at $R d=\phi=H a=\Omega=0$. Figure 2 revealed that the solutions were in good agreement.

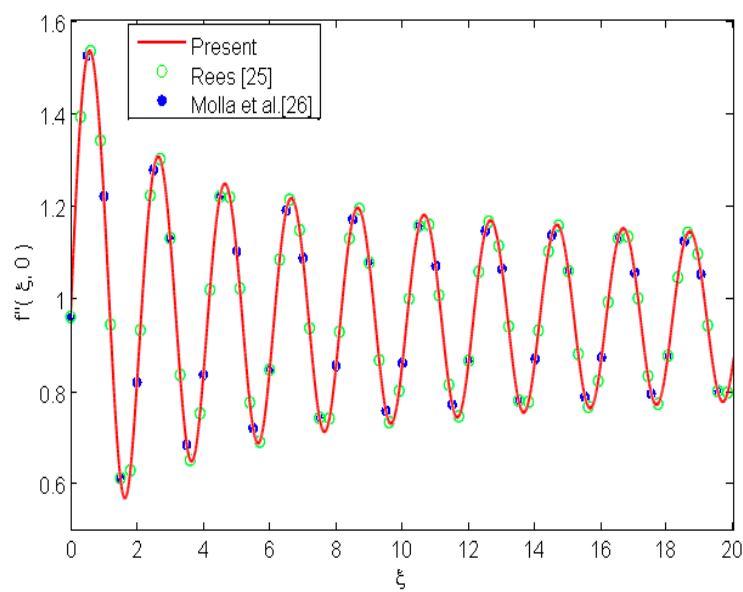

(a)

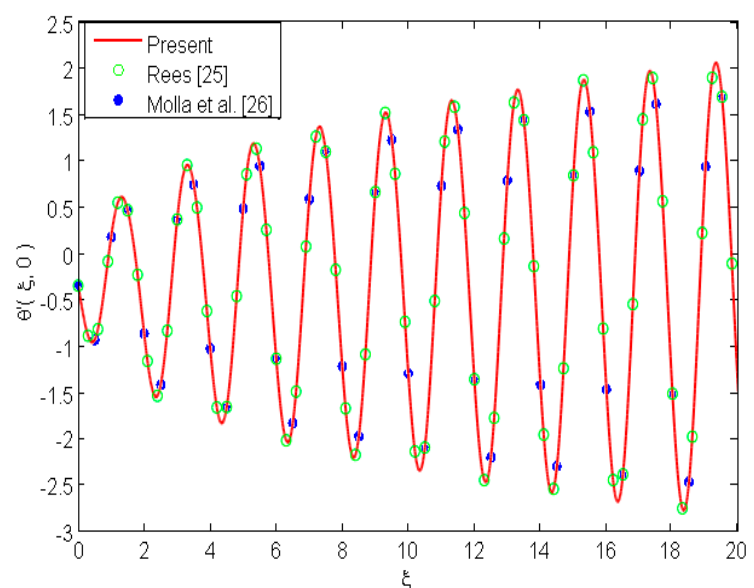

(b)

Figure 2. Comparison of Rees [25] and Molla et al. [26] for $f^{\prime \prime}(\xi, 0)(\mathbf{a})$ and $\theta^{\prime}(\xi, 0)(\mathbf{b})$ for $R d=\phi=$ $H a=\Omega=0$.

\section{Analysis of the Results}

The present section concentrates on the pertinent physical parameters' effectiveness on ferrofluid flow assign through a vertical radiate plate with the sinusoidal difference in the surface temperature. The simulated results are studied in detail and analyzed to assay the effectiveness of magnetic field $H a$, amplitude of surface temperature $\Omega$, radiation parameter $\mathrm{R}_{\mathrm{d}}$, volume fraction $\phi$, and temperature ratio parameter $\theta_{w}$ on the velocity and temperature curves, drag coefficient, and local Nusselt number. The effectiveness of $H a$ and $\Omega$ on the velocity $f^{\prime}(\xi, \eta)$ and temperature $\theta(\xi, \eta)$ curves are exhibited in Figure $3 \mathrm{a}, \mathrm{b}$. Applying a magnetic field to the ferroliquid produces a Lorentz force (dragging force) which is perpendicular to the velocity vectors. This dragging force increases the traumatizing nature 
of molecules. Also, this force declines the ferrofluid motion, in that it slows the ferrofluid velocity and boosts the temperature curves, as shown in Figure 3b. It is also apparent that the growth in the magnetic field declines/increases the momentum/thermal boundary layer thickness. On other hand, it is elucidated from these Figures that the accretion in the wave amplitude of surface temperature $\Omega$ results in a considerable altitude in the crests of velocity and temperature field. This appears because the comparatively high surface temperature produces relatively large upward fluid velocities and consequently enhances the rate of entrainment within the boundary layers. Figure $4 \mathrm{a}, \mathrm{b}$ visualizes the variations in the drag coefficient $C_{f} G r_{x}^{1 / 4} / 2$ (or $f^{\prime \prime}(\xi, 0)$ ), and local Nusselt number $N u_{x} G r_{x}^{-1 / 4}$ (or $\left.-\theta^{\prime}(\xi, 0)\right)$ with diverse values of $H a$ and $\Omega$. The graphical portrayal demonstrates that both $f^{\prime \prime}(\xi, 0)$ and $-\theta^{\prime}(\xi, 0)$ enhanced as $\Omega$ enlarged. Furthermore, it is demonstrated that the oscillation amplitude of the drag coefficient curves debilitated tardily, whilst the oscillation amplitude of $-\theta^{\prime}(\xi, 0)$ elevated as $\xi$ was boosted. Actually, the curves in Figure $4 \mathrm{~b}$ visualize that at any value of $\Omega$, there will constantly be the value of $\xi$ beyond which some portions of the heat transfer curves between consecutive surface temperature maxima shall remain positive. Furthermore, as aforementioned, the outcomes show that the growth in $\mathrm{Ha}$ yielded a considerable rise in the ferrofluid velocity and declined the temperature. This produced a depression in the drag coefficient and the Nusselt number.

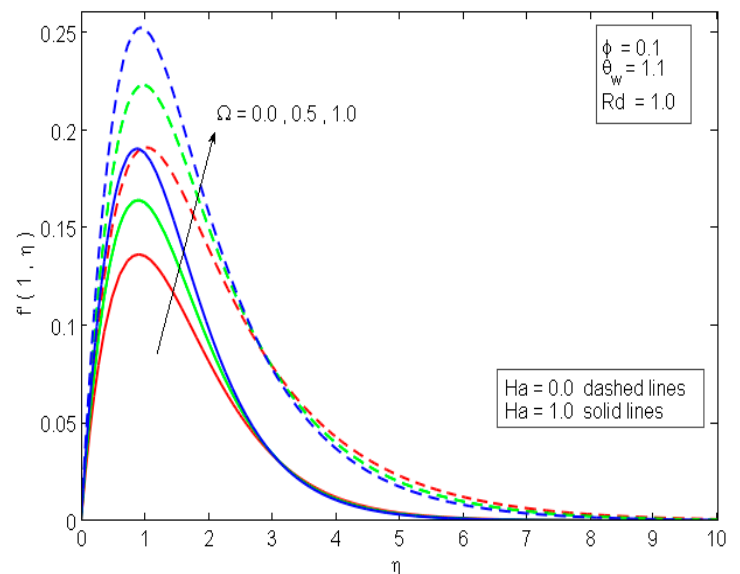

(a)

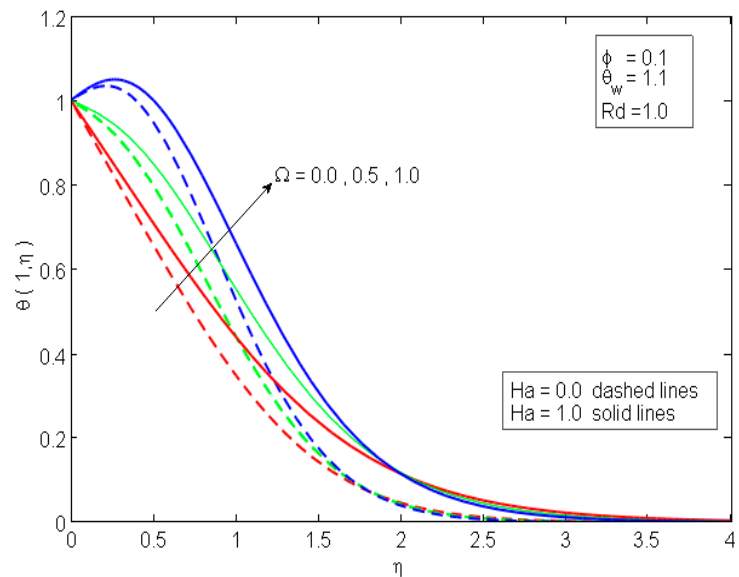

(b)

Figure 3. Effectiveness of $H a$ and $\Omega$ on velocity field (a) and on temperature field (b).

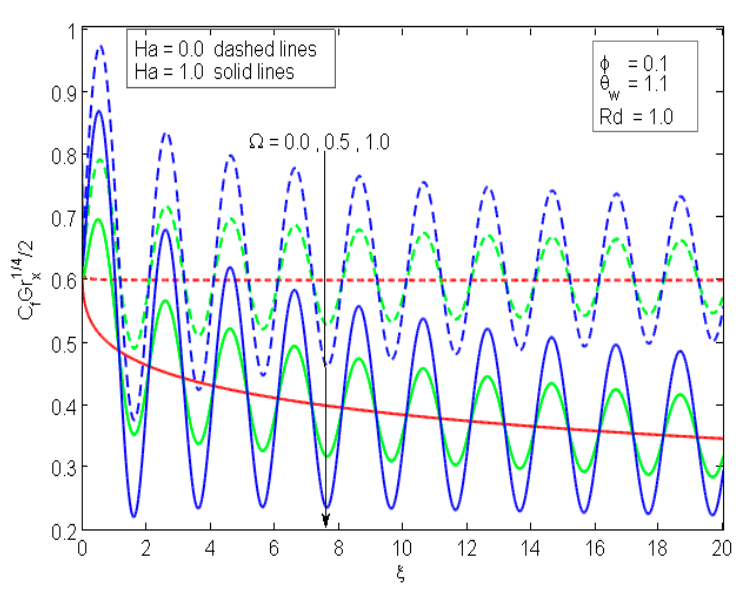

(a)

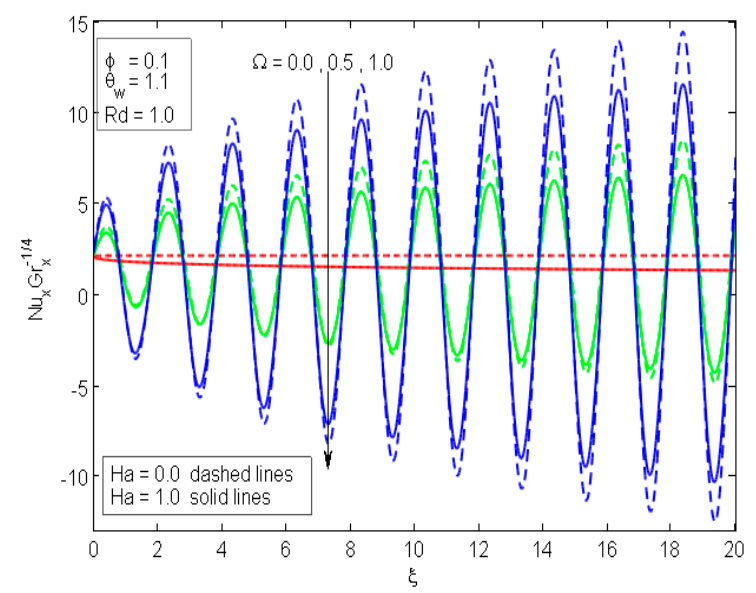

(b)

Figure 4. Effectiveness of $H a$ And $\Omega$ on drag coefficient (a) and Nusselt number (b).

Figure $5 \mathrm{a}, \mathrm{b}$ elucidates the velocity $f^{\prime}(\xi, \eta)$ and temperature $\theta(\xi, \eta)$ curves with diverse values of radiation parameter $R d$ and nanoparticle volume fraction $\phi$. It is clear that a greater value of 
thermal radiation has the potential to boost the velocity and temperature curves, as well as the momentum/thermal boundary layer thickness. This is because as $R d$ is promoted, the absorption coefficient pulls down. Hence, the heat transfer rate is boosted by radiation impact. Naturally, in the radiation operation there was additional heating to the ferrofluid, which produced an increase in temperature. Furthermore, Figure 5a elucidates that the uplifting values of $\phi$ declined the velocity nearby the surface, while the reverse behavior occurred far away from the wall, and therefore a weak evolution occurred in the momentum boundary layer thickness. Moreover, a remarkable escalation in the temperature of the ferroliquid and a dilation in the thermal boundary layer thickness was noticed as $\phi$ increased. Figure $6 \mathrm{a}, \mathrm{b}$ uncovers the reactions of $f^{\prime \prime}(\xi, 0)$ and $\theta^{\prime}(\xi, 0)$ for various values of $R d$ and $\phi$. Here, the drag coefficient diminished sufficiently as $\phi$ was boosted, and this upgraded the nanoparticles at the surface, which caused an enhancement in the heat transfer rate $\theta^{\prime}(\xi, 0)$. It was also demonstrated that both the $f^{\prime \prime}(\xi, 0)$ and $\theta^{\prime}(\xi, 0)$ were increased with an increase in $R d$.

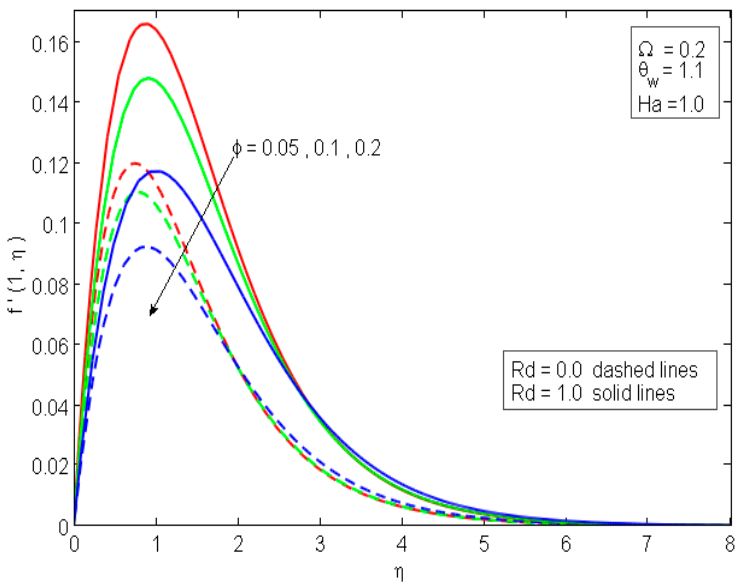

(a)

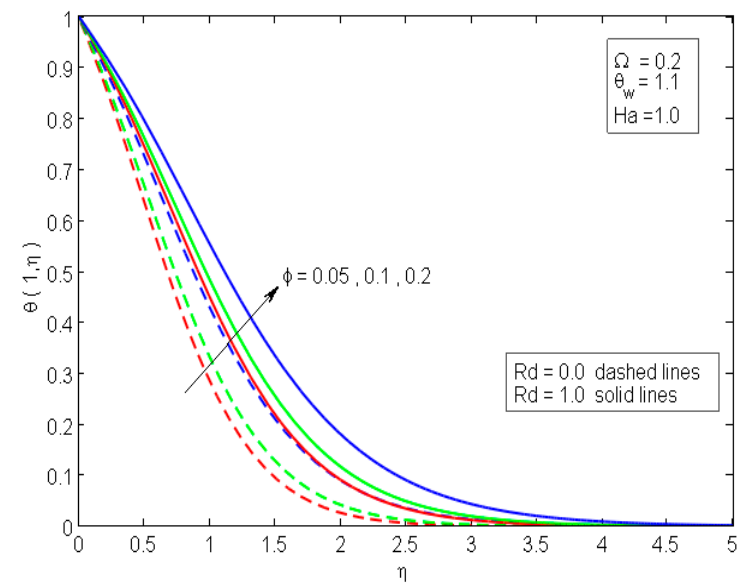

(b)

Figure 5. The effectiveness of $\phi$ and $R d$ on velocity field (a) and on temperature field (b).

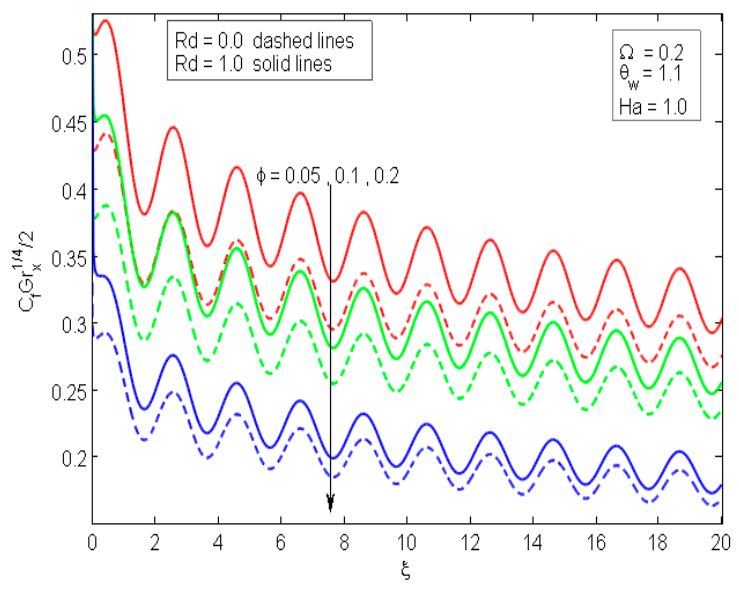

(a)

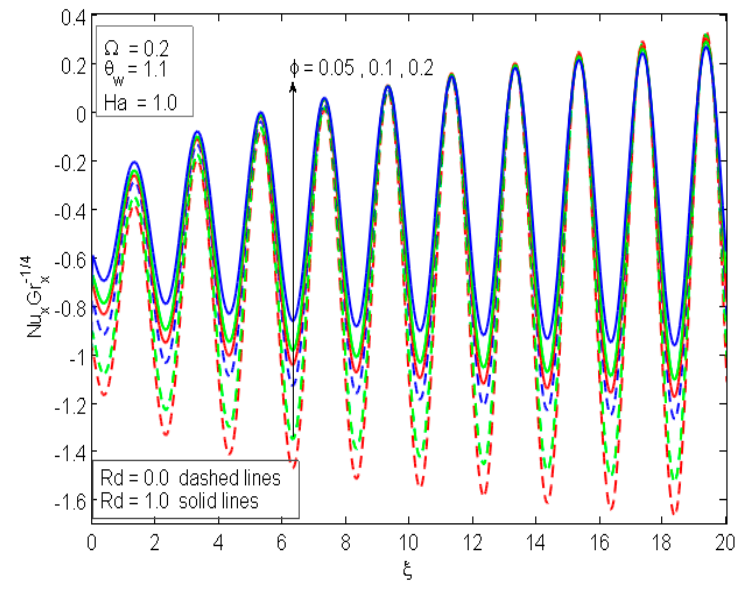

(b)

Figure 6. The effectiveness of $\phi$ and $R d$ on drag coefficient (a) and on Nusselt number (b).

Figure $7 \mathrm{a}, \mathrm{b}$ visualizes the conduct of temperature ratio parameter $\theta_{w}$ on velocity $f^{\prime}(\xi, \eta)$ and temperature $\theta(\xi, \eta)$ distributions. It can be seen that both $f^{\prime}(\xi, \eta)$ and $\theta(\xi, \eta)$ with the momentum/thermal boundary layer thickness increased when $\theta_{w}$ was boosted. Physically, the thermal diffusion of the boundary layer differed with the temperature, and it is observed that for great temperatures, the thermal boundary layer was thicker nearby the surface, whilst for lower 
temperatures it was thinner far away the surface. Figure $8 \mathrm{a}, \mathrm{b}$ portrays the drag coefficient $f^{\prime \prime}(\xi, 0)$ and Nusselt number $\theta^{\prime}(\xi, 0)$ for diverse values of $\theta_{w}$. It was found that an increase in $\theta_{w}$ indicates a considerable enhancement in both $f^{\prime \prime}(\xi, 0)$ and $\theta^{\prime}(\xi, 0)$. It is also noteworthy from Figure $8 \mathbf{b}$ that the $\theta^{\prime}(\xi, 0)$ was greater as the surface temperature decreased. This result is predictable because the increase in $\theta_{w}$ enhances the surface temperature, which results in a thicker depth for temperature.

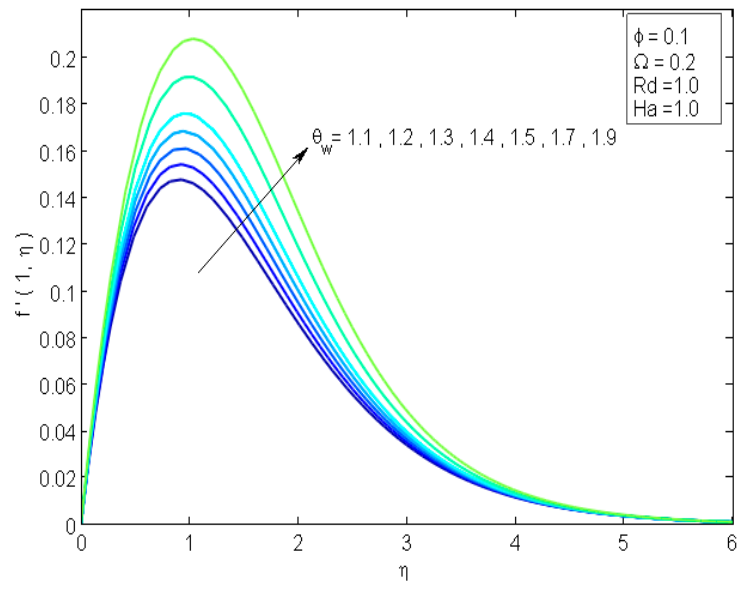

(a)

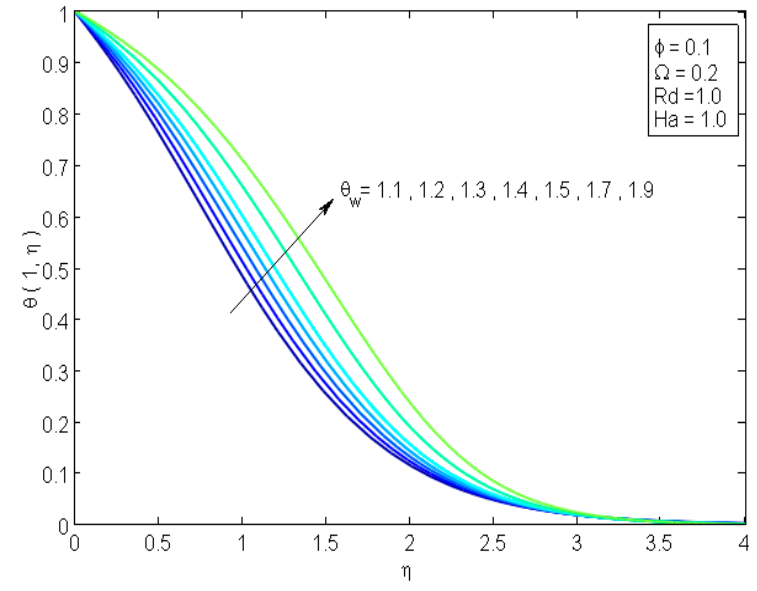

(b)

Figure 7. The effectiveness of $\theta_{w}$ on velocity field (a) and on temperature field (b).

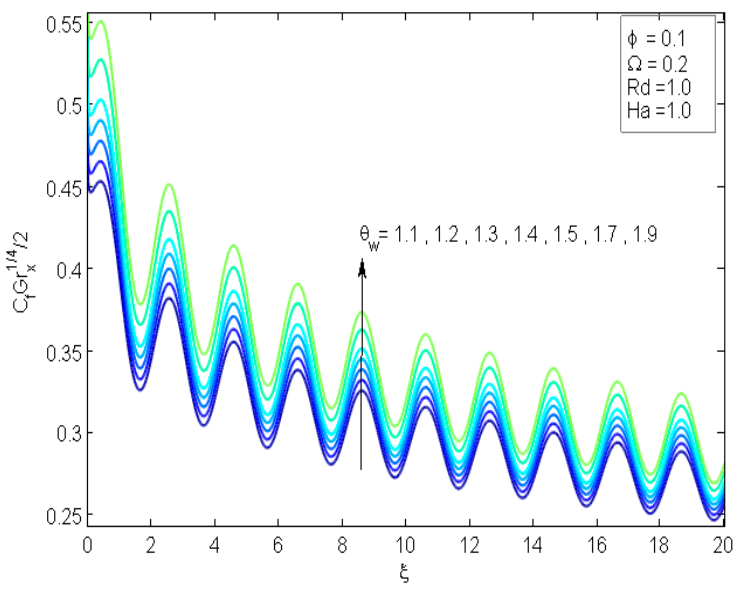

(a)

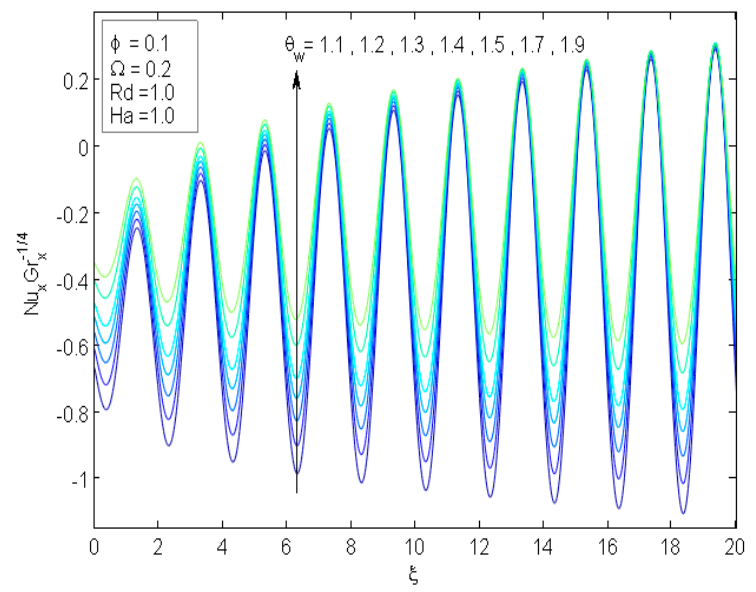

(b)

Figure 8. The effectiveness of $\theta_{w}$ on drag coefficient (a) and on Nusselt number (b).

\section{Conclusions}

The current work analyzed the impacts of magnetic field and thermal radiation on magneto-natural convective ferrofluid flow through a vertical radiate plate, applying streamwise sinusoidal diversity in surface temperature. The original equations describing the ferrofluid motion and energy equations were converted into non-dimensional equations and solved numerically using a new hybrid linearization-differential quadrature method. A comparison of the numerical solutions established by different approaches in literature and HLDQM solution revealed that the solutions were in good agreement. HLDQM results in approximate analytical solutions of the nonlinear PDEs in the $\eta$-direction, and so the solutions are valid overall in the $\eta$ domain, not only at grid points. This property allows us to easily find solutions at intermediate grid points without interpolation, and consequently different grid adaptation techniques can be used. Moreover, the technique can be utilized directly in systems of high-order differential equations with no need to convert them into first-order system. 
All the physical parameters were debated and sketched through figures. Important results are as follows:

- Applying the magnetic field to the ferroliquid generates a dragging force that decelerates the ferrofluid velocity and boosts the temperature curves;

- Higher estimations of thermal radiation have the potential to boost the velocity and temperature curves;

- The drag coefficient diminishes sufficiently, while an augmentation in the rate of heat transfer occurs as nanoparticles volume fraction builds;

- A boost in the temperature ratio parameter signifies a considerable enhancement in both the drag coefficient and local Nusselt number.

Author Contributions: Conceptualization, A.M.R., E.R.E.-Z. and L.F.S.; software, E.R.E.-Z.; validation, A.M.R., E.R.E.-Z.; formal analysis, A.M.R.; investigation, A.M.R. and E.R.E.-Z.; resources, E.R.E.-Z.; data curation, A.M.R.; writing-original draft preparation, A.M.R., E.R.E.-Z. and L.F.S.; writing-review and editing, A.M.R. and E.R.E.-Z.; supervision, A.M.R. and E.R.E.-Z.; project administration, L.F.S.; funding acquisition, E.R.E.-Z. and L.F.S.

Funding: This project was supported by the Deanship of Scientific Research at Prince Sattam bin Abdulaziz University under the research project No. 2019/01/10430.

Acknowledgments: The authors thank the anonymous referees for their careful reading of our manuscript and their insightful comments and valuable suggestions that helped to improve the manuscript.

Conflicts of Interest: The authors declare no conflict of interest.

\section{References}

1. Choi, S.U.; Eastman, J.A. Enhancing Thermal Conductivity of Fluids with Nanoparticles; Argonne National Lab.: Lemont, IL, USA, 1995.

2. Choi, S.U.; Singer, D.A.; Wang, H.P. Developments and applications of non-Newtonian flows. Asme Fed 1995, 66, 99-105.

3. Buongiorno, J. Convective transport in nanofluids. J. Heat Transf. 2006, 128, 240-250. [CrossRef]

4. Kuznetsov, A.V.; Nield, D.A. Natural convective boundary-layer flow of a nanofluid past a vertical plate: A revised model. Int. J. Therm. Sci. 2014, 77, 126-129. [CrossRef]

5. Khan, W.A.; Pop, I. Boundary-layer flow of a nanofluid past a stretching sheet. Int. J. Heat Mass Transf. 2010, 53, 2477-2483. [CrossRef]

6. Bachok, N.; Ishak, A.; Pop, I. Boundary-layer flow of nanofluids over a moving surface in a flowing fluid. Int. J. Therm. Sci. 2010, 49, 1663-1668. [CrossRef]

7. Rashad, A.M.; El-Hakiem, M.A.; Abdou, M.M. Natural convection boundary layer of a non-Newtonian fluid about a permeable vertical cone embedded in a porous medium saturated with a nanofluid. Comput. Math. Appl. 2011, 62, 3140-3151. [CrossRef]

8. Rashad, A.M.; Abbasbandy, S.; Chamkha, A.J. Non-Darcy natural convection from a vertical cylinder embedded in a thermally stratified and nanofluid-saturated porous media. J. Heat Transf. 2014, 136, 022503. [CrossRef]

9. Chamkha, A.J.; Abbasbandy, S.; Rashad, A.M.; Vajravelu, K. Radiation effects on mixed convection over a wedge embedded in a porous medium filled with a nanofluid. Transp. Porous Media 2012, 91, 261-279. [CrossRef]

10. Chamkha, A.J.; Modather, M.; EL-Kabeir, S.M.M.; Rashad, A.M. Radiative effects on boundary-layer flow of a nanofluid on a continuously moving or fixed permeable surface. Recent Pat. Mech. Eng. 2012, 5, 176-183. [CrossRef]

11. Chamkha, A.J.; Rashad, A.M. Natural convection from a vertical permeable cone in a nanofluid saturated porous media for uniform heat and nanoparticles volume fraction fluxes. Int. J. Numer. Methods Heat Fluid Flow 2012, 22, 1073-1085. [CrossRef]

12. Chamkha, A.J.; Abbasbandy, S.; Rashad, A.M.; Vajravelu, K. Radiation effects on mixed convection about a cone embedded in a porous medium filled with a nanofluid. Meccanica 2013, 48, 275-285. [CrossRef] 
13. Chamkha, A.J.; Rashad, A.M.; Aly, A.M. Transient natural convection flow of a nanofluid over a vertical cylinder. Meccanica 2013, 48, 71-81. [CrossRef]

14. Chamkha, A.J.; Rashad, A.M.; EL-Zahar, E.R.; EL-Mky, H.A. Analytical and Numerical Investigation of Fe 3 $\mathrm{O}_{4}$-Water Nanofluid Flow over a Moveable Plane in a Parallel Stream with High Suction. Energies 2019, 12, 198. [CrossRef]

15. Mahajan, A.; Sharma, M.K. Convection in magnetic nanofluids in porous media. J. Porous Media 2014, 17, 439-455. [CrossRef]

16. Sheikholeslami, M.; Rashidi, M.M. Ferrofluid heat transfer treatment in the presence of variable magnetic field. Eur. Phys. J. Plus 2015, 130, 115. [CrossRef]

17. Sheikholeslami, M.; Rashidi, M.M.; Ganji, D.D. Numerical investigation of magnetic nanofluid forced convective heat transfer in existence of variable magnetic field using two-phase model. J. Mol. Liq. 2015, 212, 117-126. [CrossRef]

18. Sheikholeslami, M.; Rashidi, M.M.; Hayat, T.; Ganji, D.D. Free convection of magnetic nanofluid considering MFD viscosity effect. J. Mol. Liq. 2016, 218, 393-399. [CrossRef]

19. Chamkha, A.J.; Rashad, A.M. MHD forced convection flow of a nanofluid adjacent to a non-isothermal wedge. Comput. Therm. Sci. 2014, 6, 27-39. [CrossRef]

20. Kumar, K.G.; Ramesh, G.K.; Gireesha, B.J.; Rashad, A.M. On stretched magnetic flow of Carreau nanofluid with slip effects and nonlinear thermal radiation. Nonlinear Eng. 2019, 8, 340-349. [CrossRef]

21. Hayat, T.; Imtiaz, M.; Alsaedi, A.; Kutbi, M.A. MHD three-dimensional flow of nanofluid with velocity slip and nonlinear thermal radiation. J. Magn. Magn. Mater. 2015, 396, 31-37. [CrossRef]

22. Hayat, T.; Muhammad, T.; Alsaedi, A.; Alhuthali, M.S. Magnetohydrodynamic three-dimensional flow of viscoelastic nanofluid in the presence of nonlinear thermal radiation. J. Magn. Magn. Mater. 2015, 385, 222-229. [CrossRef]

23. Rashad, A.M. Impact of thermal radiation on MHD slip flow of a ferrofluid over a non-isothermal wedge. J. Magn. Magn. Mater. 2017, 422, 25-31. [CrossRef]

24. Waqas, M.; Khan, M.I.; Hayat, T.; Alsaedi, A. Numerical simulation for magneto Carreau nanofluid model with thermal radiation: A revised model. Comput. Methods. Appl. Mech. Eng. 2017, 324, 640-653. [CrossRef]

25. El-Kabeir, S.M.; El-Zahar, E.R.; Modather, M.; Gorla, R.S.; Rashad, A.M. Unsteady MHD slip flow of a ferrofluid over an impulsively stretched vertical surface. AIP Adv. 2019, 9, 045112. [CrossRef]

26. Rees, D.A. The effect of steady streamwise surface temperature variations on vertical free convection. Int. J. Heat Mass Transf. 1999, 42, 2455-2464. [CrossRef]

27. Molla, M.M.; Saha, S.C.; Hossain, M.A. Radiation effect on free convection laminar flow along a vertical flat plate with streamwise sinusoidal surface temperature. Math. Comput. Model. 2011, 53, 1310-1319. [CrossRef]

28. Bert, C.W.; Malik, M. Differential quadrature method in computational mechanics: A review. Appl. Mech. Rev. 1996, 49, 1-28. [CrossRef]

29. Shu, C. Differential Quadrature and Its Application in Engineering; Springer Science \& Business Media: Berlin, Germany, 2012.

30. Zong, Z.; Zhang, Y. Advanced Differential Quadrature Methods; Chapman and Hall/CRC: London, UK, 2009.

31. Nassar, M.; Matbuly, M.S.; Ragb, O. Vibration analysis of structural elements using differential quadrature method. J. Adv. Res. 2013, 4, 93-102. [CrossRef]

32. Jiwari, R.; Gupta, R.K.; Kumar, V. Polynomial differential quadrature method for numerical solutions of the generalized Fitzhugh-Nagumo equation with time-dependent coefficients. Ain Shams Eng. J. 2014, 5, 1343-1350. [CrossRef]

33. Korkmaz, A.; Dag, I. Polynomial based differential quadrature method for numerical solution of nonlinear Burgers' equation. J. Frankl. Inst. 2011, 348, 2863-2875. [CrossRef]

34. Mohammed, O.H.; Saeed, M.A. Numerical solution of thin plates problem via differential quadrature method using G-spline. J. King Saud Univ. Sci. 2019, 31, 209-214. [CrossRef]

35. Mohamed, N.; Eltaher, M.A.; Mohamed, S.A.; Seddek, L.F. Energy equivalent model in analysis of postbuckling of imperfect carbon nanotubes resting on nonlinear elastic foundation. Struct. Eng. Mech. 2019, 70, 737-750.

36. Eltaher, M.A.; Mohamed, N.; Mohamed, S.A.; Seddek, L.F. Periodic and nonperiodic modes of postbuckling and nonlinear vibration of beams attached to nonlinear foundations. Appl. Math. Model. 2019, 75, 414-445. [CrossRef] 
37. Eltaher, M.A.; Mohamed, N.; Mohamed, S.; Seddek, L.F. Postbuckling of curved carbon nanotubes using energy equivalent model. J. Nano Res. 2019, 57, 136-157. [CrossRef]

38. Mohamed, N.; Eltaher, M.A.; Mohamed, S.A.; Seddek, L.F. Numerical analysis of nonlinear free and forced vibrations of buckled curved beams resting on nonlinear elastic foundations. Int. J. Non-Linear Mech. 2018, 101, 157-173. [CrossRef]

39. Ragb, O.; Seddek, L.F.; Matbuly, M.S. Iterative differential quadrature solutions for Bratu problem. Comput. Math. Appl. 2017, 74, 249-257. [CrossRef]

(C) 2019 by the authors. Licensee MDPI, Basel, Switzerland. This article is an open access article distributed under the terms and conditions of the Creative Commons Attribution (CC BY) license (http://creativecommons.org/licenses/by/4.0/). 